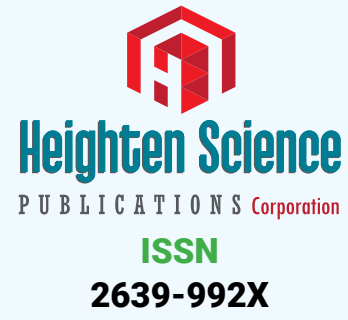

*Address for Correspondence: Mariela Fernanda Pérez, IFEC-Departamento de Farmacología, Facultad de Ciencias Químicas, CONICET, Universidad Nacional de Córdoba, Haya de la Torre y Medina Allende s/n, Ciudad Universitaria, 5000, Córdoba, Argentina, Email:

mfperez@fcq.unc.edu.ar

Submitted: 23 December 2017

Approved: 05 January 2018

Published: 08 January 2018

Copyright: @2018 Artur de la Villarmois E, et

al. This is an open access article distributed under the Creative Commons Attribution License, which permits unrestricted use, distribution, and reproduction in any medium, provided the original work is properly cited.

Keywords: Diazepam; Withdrawal; NOS-1, Nitric oxide, Hippocampal plasticity

Abbreviations: BZD: Benzodiazepines; CR: Conditioned Response; CS: Conditioned Stimulus; DZ: Diazepam; EPM: Elevated PlusMaze; EPSPs: Excitatory Postsynaptic Potentials HP: Hippocampus; i.p: Intraperitoneal; LI: Latent Inhibition; LTP: Long-Term Potentiation; NMDA N-Methyl-D-Aspartate; NO: Nitric Oxide; NOS-1: Neuronal Nitric Oxide Synthase; OD: Optical Density; \%TA: percentage of Time spent on the open Arms; US: Unconditioned Stimulus; UR: Unconditioned Response; VEHIC: Vehicle

Check for updates
Research Article

\section{Diazepam Withdrawal Expression is related to Hippocampal NOS-1 Upregulation}

\author{
Emilce Artur de la Villarmois, María Florencia Constantin, \\ Claudia Bregonzio and Mariela Fernanda Pérez* \\ IFEC-Departamento de Farmacología, Facultad de Ciencias Químicas, CONICET, Universidad \\ Nacional de Córdoba, Haya de la Torre y Medina Allende s/n, Ciudad Universitaria, Córdoba, \\ Argentina
}

\section{Abstract}

Background: Benzodiazepines are usually prescribed for anxiety and sleep disorders in a long-term fashion that may cause drug dependence. Discontinuation after prolonged administration may lead to withdrawal expression, being anxiety the most predominant sign. It has been described that a contextdependent associative learning process underlies diazepam dependence. Nitric oxide is a crucial player in learning and memory processes, hippocampal transmission, as well as in benzodiazepines withdrawal. Considering that previous results from our laboratory showed an increase in hippocampal functional plasticity only in diazepam dependent rats, the aim of the present investigation is to determine whether diazepam dependence could alter neuronal nitric oxide synthase enzyme (NOS-1) expression within the hippocampus, by using western blot.

Results: chronic diazepam-treated animals that developed dependence showed increase in NOS-1 expression in dorsal, but not in ventral hippocampus, while no-dependent or control animals presented similar NOS-1 protein levels.

Conclusion: withdrawal from long-term diazepam exposure could be associated to increased nitric oxide neurotransmission within dorsal hippocampus induced by NOS-1 over-expression. This mechanism could underlie the improved hippocampal synaptic transmission previously observed in diazepam withdrawn animals. Confirmatory experiments need to be addressed to determine the mechanisms by which nitric oxide participates in benzodiazepines withdrawal in order find new molecular targets to develop pharmacological tools to prevent the withdrawal syndrome.

\section{Introduction}

Benzodiazepines are commonly prescribed for the treatment of anxiety and sleep disorders. However, prolonged treatment may lead to dependence with evident withdrawal syndrome [1-3]. Long-lasting neuroadaptations resulting from repeated drug exposure involve an associative learning process [4-7]. These learning and cognitive aspects of addiction suggest the existence of common neurobiological mechanisms mediating drug addiction and memory [5,8-10]. Both phenomena are accompanied by alterations in synaptic plasticity at glutamate synapses in the reward pathway, involving the ventral tegmental area, nucleus accumbens, and frontal cortex $[8,11]$. In addition to the relevance of the reward circuitry in the development of addiction, other brain areas such as the hippocampus (HP) have been implicated [12]. This brain structure plays a great role in processing the associations between the environmental context and unconditioned stimuli such as drugs of abuse [13]. Within the HP, the long-term potentiation (LTP) characterized by an enduring increase in the efficacy of glutamatergic synaptic transmission is a major form of synaptic plasticity. This phenomenon is accepted as a molecular mechanism for learning and memory in the brain in which contextual cues are relevant $[14,15]$. We have previously described

How to cite this article: Artur de la Villarmois E, Constantin MF, Bregonzio C, Pérez MF. Diazepam Withdrawal Expression is related to Hippocampal NOS-1 Upregulation. Arch Pharm Pharma Sci. 2018; 2: 001-009. https://doi.org/10.29328/journal.hps.1001006 
that Diazepam (DZ) dependence was related to a marked and sustained enhancement in the HP dentate gyrus synaptic transmission $[6,16]$, supporting the relevance of HP synaptic plasticity in maintenance of the memory trace during BZD withdrawal.

Neuronal excitability and synaptic plasticity in HP and other brain areas, are modulated by nitric oxide (NO) [17]. NO is a diffusible neuromodulator synthesized in the brain mainly by the neuronal NO synthase enzyme (NOS-1) following glutamatergic N-Methyl-D-Aspartate (NMDA) receptor activation [18], and it is involved in a variety of physiological and pathophysiological processes including nociception [19], neurogenesis [20], learning and memory [21], anxiety [22] and seizure activity [23]. Furthermore, NO activated pathways contribute to neuronal adaptations induced by different addictive drugs [24-26] and inhibition of NO synthesis attenuates pentetrazole-induced withdrawal syndrome in diazepam-dependent mice [27], and reduces withdrawal expression from psych stimulants [28], nicotine [29], opioids [30,31], ethanol [32]. Then, considering that the evidence regarding participation of NOS-1 in BZD withdrawal is based on pharmacological and behavioral results, the aim of the present investigation is to characterize possible changes in NOS-1 expression within the HP induced by DZ dependence.

\section{Materials and Methods}

\section{Ethical statement}

All procedures were carried out in accordance with the National Institute of Health Guide for the Care and Use of Laboratory Animals (NIH Publications No. 80-23) revised 1996 and by the ARRIVE guidelines of the National Centre for the Replacement, Refinement, and Reduction of Animals in Research (2011) adopted by NIH. All protocols were approved by the Animal Care and Use Committee, School of Chemical Sciences, National University of Cordoba (RES-48-2015). Experiments were made minimizing the number of animals used and their suffering.

\section{Animals}

Male Wistar rats of 5-6 weeks old at the beginning of the treatment, obtained from the Department of Pharmacology- IFEC CONICET vivarium (Facultad de Ciencias Químicas, Universidad Nacional de Córdoba, Argentina) were used. Animals were housed in groups of 3 , in plastic boxes with metallic gridded tops, using sawdust as bedding material, in a temperature and humidity controlled conditions under a 12 -h light/dark cycle (light on at $7 \mathrm{am}$ ). Food and water were freely available.

\section{Drugs}

Commercially available ampoules of DZ $(10 \mathrm{mg} / 2 \mathrm{ml}$, Klonal SRL, Argentina) were used. Vehicle (VEHIC) was prepared using distilled water with Tween 80 (0.3\%, Sigma Aldrich-Fluka, Argentina) and propilenglycol (5\%, Sintorgan SA, Argentina). Saline solution was prepared at $0.9 \% \mathrm{NaCl}$.

\section{Experimental protocol}

Animals received DZ $(5 \mathrm{mg} / \mathrm{kg} /$ day, $\mathrm{n}=32)$ or VEHIC $(\mathrm{n}=10)$ via intraperitoneal (i.p.) along 18 days (Figure 1a). This procedure was performed by the same operator, in the same room location and with a specific piece of fabric used along the treatment. Forty eight hs. After the last DZ or VEHIC administration, animals were evaluated in the elevated plus-maze (EPM) test to evidence an "anxiety-like behavior" as a sign of the withdrawal syndrome. Immediately after the EPM, a group of rats $(n=16)$ were sacrificed for western blot experiments, by guillotine decapitation.

\section{Elevated plus maze test}

The EPM apparatus consisted of two opposite open arms $(50 \times 10 \mathrm{~cm})$, and two opposite enclosed arms, $(50 \times 10 \times 40 \mathrm{~cm})$, with an open roof arranged. The arms 
extended from a central platform $(10 \times 10 \mathrm{~cm})$ and the apparatus was elevated to a height of $50 \mathrm{~cm}$. Rats were placed in the center of the maze during $5 \mathrm{~min}$ and different dependent variables were analyzed using the method previously reported. These variables include percentage of time spent on the open arms (\%TA), entries and extreme arrivals in open arms, which served as index of anxiety. Also, the entries in closed arms were measured as loco motor activity index.

\section{Western blot}

Immediately after the EPM test animals were sacrificed by guillotine decapitation, their brains were quickly removed and placed on ice. Coronal brain slices of $2 \mathrm{~mm}$ containing dorsal or ventral HP were prepared, homogenized in a lysis buffer containing protease and phosphatase inhibitors, the homogenate were centrifuged at $12000 \mathrm{~g}$ for $10 \mathrm{~min}$ at $4{ }^{\circ} \mathrm{C}$. The supernatant was combined with Laemmli's buffer, boiled at $100{ }^{\circ} \mathrm{C}$ for $5 \mathrm{~min}$ and stored in aliquots at $-20^{\circ} \mathrm{C}$ until use. Aliquots of the supernatant were used for total protein quantification using the Bradford's method. Samples $(70 \mu \mathrm{g}$ of protein) were separated in $8 \%$ SDS-PAGE gel, and transferred to polivinylidenedifluoride membranes in a Tris-glycine buffer, $20 \%$ methanol. Membranes were cut at $75 \mathrm{kDa}$ in order to incubate NOS-1 (160kDa) and actin $(43 \mathrm{kDa})$ with their respective antibodies. Then, they were incubated overnight at $4{ }^{\circ} \mathrm{C}$ with a previously characterized, commercially available NOS-1 antibody (1:500; Cell Signaling Technology, Cat \#4234), and actin antibody (1:1000; Santa Cruz Biotechnology, INC. Cat\# sc-1616), the next day membranes were subsequently incubated with the corresponding anti-rabbit antibody (1:20000; IRDye $800 \mathrm{wc}$ ) and anti-goat antibody (1:20000; IRDye $680 \mathrm{LD}$ ) for $2 \mathrm{~h}$ at room temperature. The membranes were scanned (Odyssey CLx, LI-COR) and the value of optical density (OD) of each band was quantified with an image analysis program (GelPro32 Analyzer). The actin expression was used as internal control and results are expressed as OD NOS-1/OD actin.

\section{Statistical Analyses}

Results from EPM and western blots were analyzed by one-way ANOVA, followed by the post hoc Newman-Keuls pairwise comparisons of means. Pearson's correlation was used to analyze the correlation between \%TA and NOS-1 protein levels. Analyses were performed using GraphPad Prism 6. Data were expressed as the means \pm SE. The significance level used for all statistical analyses was set at $\mathrm{p}<0.05$.

\section{Results}

Long-term diazepam administration induced "anxiety like" behavior in a proportion of treated rats $48 \mathrm{hs}$ after last administration

It has been previously described that the "anxiety like" behavior as a sign of DZ withdrawal during the first exposure to the EPM, after 18 days of DZ administration, can be observed until 4 days after the last injection [6]. In the present work, we reproduced those results showing that an "anxiety like" behavior was observed 48 hs after the last DZ administration, assessed by \% of time spent in open arms (\%TA), entries and extreme arrivals in open arms, in a proportion of treated animals (dependent animals). An animal was considered "anxious" or dependent [DZ(D), n=13] if the \%TA was less than $13 \%$, above this percentage animals were considered as non-dependent [DZ(ND), $\mathrm{n}=19]$. This criterion was adopted considering the hippocampal synaptic transmission results after this treatment [16]. The one-way ANOVA showed a significant differences on the $\% \mathrm{TA}\left[\mathrm{F}_{(2,39)}=50.5 ; \mathrm{p}=0.0001\right]$ (Figure $1 \mathrm{~b}$ ). Newman-Keuls pairwise comparisons of means showed that the \% TA was significantly lower in DZ(D) $(5.0 \pm 1.4, \mathrm{n}=13)$ when compared to VEHIC $(32.87 \pm 2.78, \mathrm{n}=10)$ or $\mathrm{DZ}(\mathrm{ND})\left(27.06 \pm 1.91, \mathrm{n}=19,{ }^{*} \mathrm{p}<0.05\right)$. No differences were found between DZ(ND) and VEHIC ( $p>0.05)$. When the open arms entries were analyzed (Figure 1d), a significant effect was observed between groups $\left[F_{(2,39)}=6.79 ; p=0.003\right]$. Newman-Keuls pairwise comparisons of means showed that 
open arms entries was significantly lower in DZ(D) $(0.38 \pm 0.15)$ when compared to VEHIC $(1.6 \pm 0.36)$ or DZ(ND) $\left(1.21 \pm 0.2,{ }^{*} \mathrm{p}<0.05\right)$. No differences were found between DZ(ND) and VEHIC ( $>0.05)$. Also, a significant effect was observed on the extreme arrivals $\left[\mathrm{F}_{(2,39)}=22.16 ; \mathrm{p}=0.0001\right]$ (Figure 1e). Moreover Newman-Keuls pairwise comparisons of means showed that extreme arrivals were significantly lower in DZ(D) $(0.54 \pm 0.25)$ when compared to VEHIC $(3.2 \pm 0.47)$ or DZ(ND) $\left(2.63 \pm 0.23,{ }^{*} \mathrm{p}<0.05\right)$. No differences were found between DZ(ND) and VEHIC groups ( $p>0.05)$. On the other hand, no differences were found on the closed arms entries between groups $\left[\mathrm{F}_{(2,39)}=\right.$ 0.98; $\mathrm{p}=0.079$ ] (Figure 1c). These results indicate that no changes were observed in loco motor activity between groups.

\section{Hippocampal NOS-1 expression in diazepam treated animals.}

It has been shown that systemic non-selective NOS-1 inhibition exerts an inhibitory effect on some of the signs of BZD withdrawal in mice and rats [27]. In order to evaluate how chronic DZ administration may induce possible alterations within the NO system, we measured NOS-1 protein expression within the dorsal or ventral HP. The one-way ANOVA on the NOS-1 protein levels in dorsal HP indicated significant differences between groups $\left[\mathrm{F}_{(2,13)}=6.21 ; \mathrm{p}=0.013\right]$ (Figure 2a). Newman-Keuls pairwise comparisons of means showed that NOS-1 expression was significantly higher in DZ(D) (1.2 \pm 0.1 OD, $n=3)$ when compared to DZ(ND) $(0.72 \pm 0.08$ OD, $n=5)$ or VEHIC $\left(0.79 \pm 0.07 \mathrm{OD}, \mathrm{n}=8,{ }^{*} \mathrm{p}<0.05\right)$. No differences were found between VEHIC and DZ(ND) ( $p>0.05)$. On the other hand, in ventral HP the one-way ANOVA showed no significant differences on the NOS-1 protein levels $\left[\mathrm{F}_{(2,11)}=0.57 ; \mathrm{p}=0.581\right]$ between groups (DZ(D) $1.55 \pm 0.39$ OD, $n=4$; DZ(ND) 1.48 \pm 0.23 OD n=5; VEHIC 1.19 \pm 0.24 OD n=5). Interestingly, when we analyzed the relationship between \%TA and NOS-1 protein levels in DZ(D) and DZ(ND) groups, a negative correlation was observed in dorsal HP between those parameters (Pearson's correlation $r=-0.87$; $\mathrm{p}=0.0048$; Figure $2 \mathrm{~b}$ ). No correlation was observed in ventral HP (Pearson's correlation $r=-0.08$; $p=0.8305$; Figure 2c,2d).

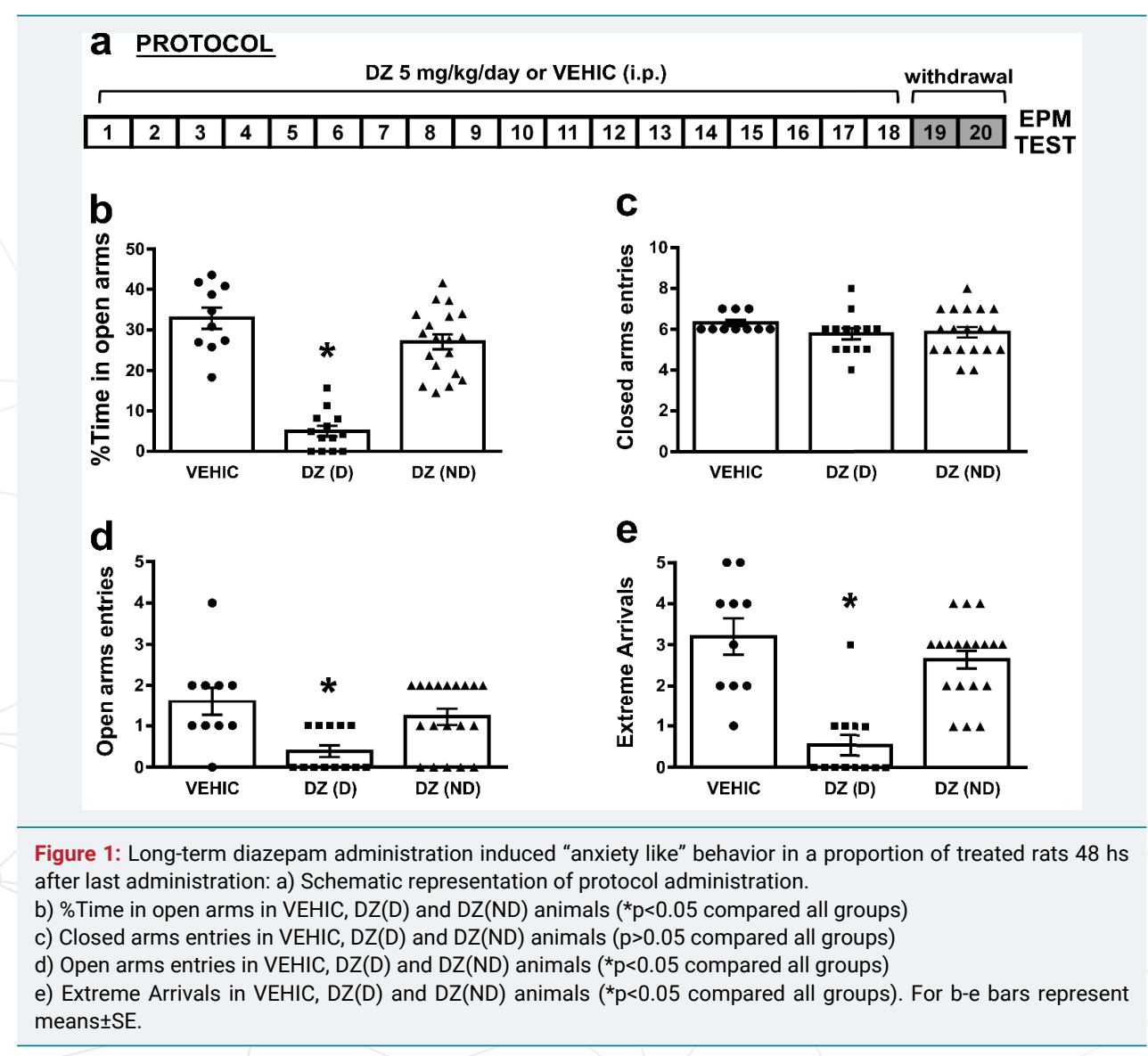




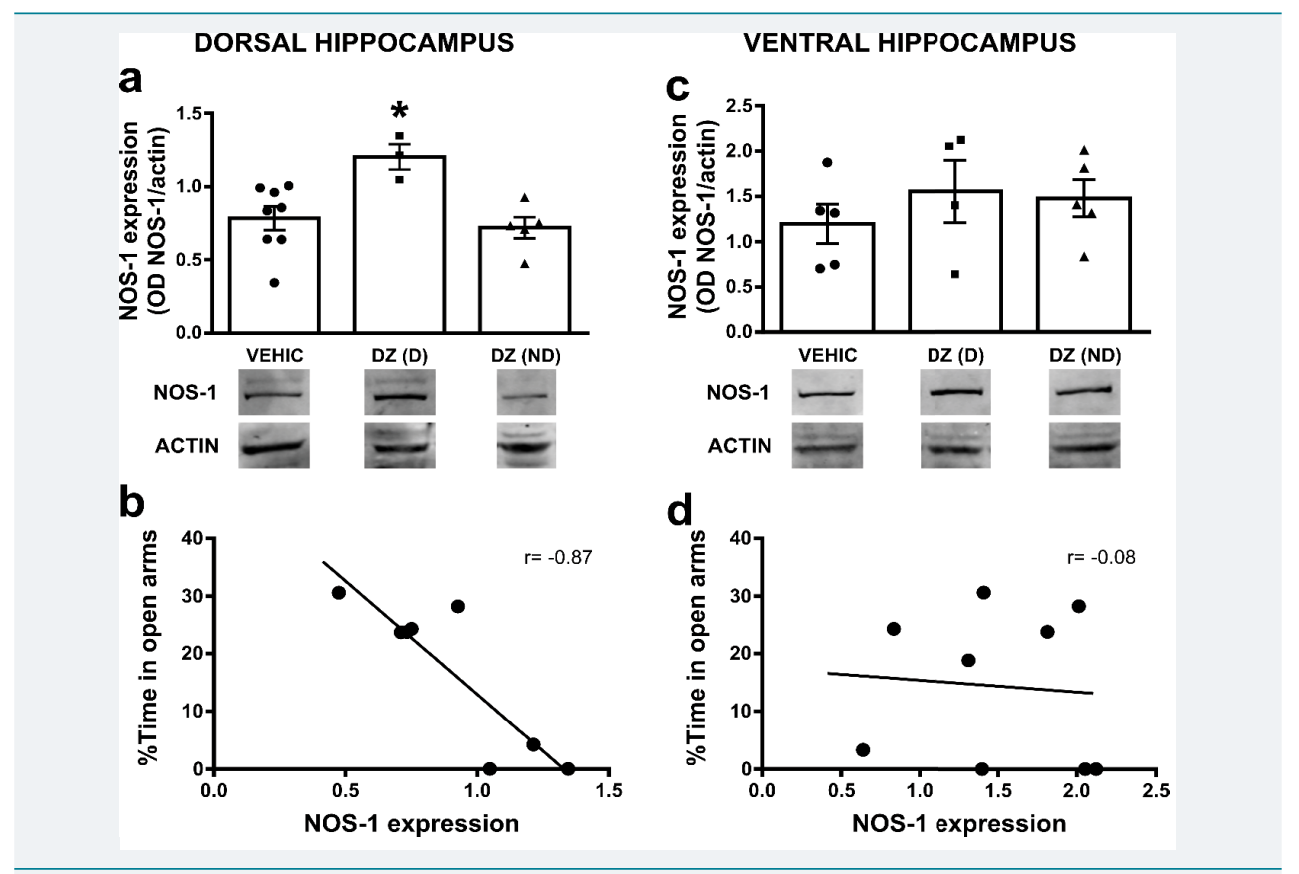

Figure 2: Hippocampal NOS-1 expression in diazepam treated animals: a) Bar graphs show NOS-1 expression (OD, optical density, NOS-1/actin) in VEHIC, DZ(D) and DZ(ND) animals in dorsal HP ( ${ }^{*} p<0.05$ compared to all groups).

b) Graphs show correlation between the \%TA and NOS-1 expression in DZ(D) and DZ(ND) in dorsal HP. The correlation coefficients $(r)$ are indicated inside the graph.

c) Bar graphs show NOS-1 expression (OD, optical density, NOS-1/actin) in VEHIC, DZ(D) and DZ(ND) animals in ventral HP.

d) Graphs show correlation between the \%TA and NOS-1 expression in DZ(D) and DZ(ND) in ventral HP. The correlation coefficients $(r)$ are indicated inside the graph. In both a and $c$, bars represent means $\pm S E$ and below each graph representative western blot for NOS-1 and actin immunoreactivity are shown. Full-length blots from cropped VEHIC, DZ(D) and DZ(ND) in dorsal and ventral HP are shown in supplementary figure $1 \mathrm{a}$ and $1 \mathrm{~b}$ respectively.

\section{Discussion}

Drug dependence is often related to a contextual learning phenomenon [33], and seems to be the principal mechanism underlying BZD dependence, in which the contextual environment during drug administration have a preponderant role in establishment of physical dependence and withdrawal in both animals and humans $[4,34]$. The HP, through its connections with structures such as the Amygdala or the medial Prefrontal Cortex, among others, is a brain structure implicated in contextual conditioning [35]. Furthermore, the anxiogenic effect promoted by DZ withdrawal was accompanied by significant Fos-positive immunoreactivity in telencephalic, diencephalic and mesencephalic areas related to anxiety and fear circuits in the brain [36], as well as to enhanced Locus Coeruleus and Dorsal Raphe Nucleus neuronal activity $[16,37]$. All these changes may contribute not only to the physical withdrawal symptoms involving autonomic function, but also to the increased HP plasticity that has been described to underlie DZ dependence and withdrawal $[6,16,38]$. Previous reports from our laboratory showed that the increased HP plasticity observed during DZ dependence is positively associated to the expression of the behavioral signs of DZ withdrawal; while absence of anxiety-like behavior is associated to HP synaptic transmission comparable to control values $[4,6,16]$. Moreover, considering the role of NMDA receptors in several types of learning, it seems likely that these receptors participate in the conditioning of the behavioral activation observed after chronic psychoactive drug treatments [39-41]. In fact, administration of MK-801, a noncompetitive NMDA receptor antagonist, impairs the development of tolerance to DZ and other psychoactive drugs [42-44], prevents the enhanced HP synaptic plasticity and the increased mRNA for the NR1-NR2B NMDA receptor subunit associated with the development of tolerance to DZ [45].

In this scenario, NO synthesized upon NMDA receptor stimulation [46], seems to play an important role not only in learning and memory processes [47] and HP LTP 
[48], but also contribute to the neuronal adaptations induced by different addictive [24-26,49]. Indeed, likewise to the MK-801 effects, inhibition of NO synthesis reduces withdrawal expression from psychostimulants [28], nicotine [29], opioids [30,31,50], ethanol [32] and BZD [27]. Furthermore, chronic nicotine withdrawal increases NOS-1 immunoreactivity in the Dorsal Raphe Nueclues and Locus Coeruleus of adult rats [51]. In the present work, we showed that chronic DZ increases NOS-1 protein levels within the dorsal HP only in dependent animals (DZ(D)), while non-dependent animals did not show alterations in NOS-1 protein levels compared to control rats. This result is in agreement with previous findings indicating that acute inhibition of NO synthesis decreases anxiety in the EPM test in rats [52], while augmentation of the NO-activated cascade induces anxiogenic-like effect in mice [53]. The dorsal HP is a region primarily involved in the cognitive process of learning and memory [54], and it is important to note that the increase in NOS-1 protein levels was only observed in this region and not in ventral HP.

Analyzing previous reports together with the present behavioral and molecular results, a negative and significant correlation was observed between "anxiety like" behavior and NOS-1 expression within dorsal HP, supporting previous results in which low levels of \%TA were related to increased HP transmission and now with high NOS1 protein levels. These augmented protein levels may indicate that NOS-1 enzyme evidenced a neuroadaptative process after repeated administration, in which activation of NMDA receptors during chronic DZ exposure may lead to a NO overproduction that up-regulates NOS-1 protein expression within HP, explaining at least in part, maintenance of high levels of HP synaptic plasticity during long term DZ withdrawal [6], as well as expression of the "anxiety like" behavior. However, we cannot discharge that changes in NOS-1 levels or synaptic transmission in other brain structures may account for expression of DZ withdrawal.

\section{Conclusions}

Long-term DZ exposure seems to be able to induce functional and molecular changes within the HP, such as enhanced synaptic transmission probably by increases of NO availability, and consequently contribute with the learning and memory processes that underlie BZD dependence. Further studies need to be conducted in order to confirm the causal relationship between BZD withdrawal expression, HP synaptic transmission and NO signaling, as well as to characterize other mechanism and/or brain structures involved in this process and the molecular pathways by which NO participates in BZD dependence in order to find new molecular targets to design pharmacological tools to prevent DZ dependence and withdrawal.

\section{Acknowledgements}

We thank Tec. Lorena Mercado and Estela Salde who assisted us with western blot experiments.

\section{Support statement}

This work was supported by SECyT [grant number 30720150100437CB, 20162017]; and CONICET [grant number PIP 2013-2015. № 1122012 0100373CO KB1]. These funding agencies had no further role in study design; in the collection, analysis and interpretation of data; in the writing of the report; and in the decision to submit the paper for publication.

\section{Data accessibility}

Statistical tools, protocols, suppliers and data presented within the manuscript are sufficient to fully reproduce results of the article. 


\section{References}

1. Greenblatt DJ, Shader RI. Dependence, tolerance, and addiction to benzodiazepines: clinical and pharmacokinetic considerations. Drug Metab Rev. 1978; 8: 13-28. Ref.: https://goo.gl/E5Z8uo

2. Dickinson B, Rush PA, Radcliffe AB. Alprazolam use and dependence. A retrospective analysis of 30 cases of withdrawal. West J Med. 1990; 152: 604-608. Ref.: https://goo.gl/udDKN5

3. Quaglio G, Pattaro C, Gerra G, Mathewson S, Verbanck P, et.al. High dose benzodiazepine dependence: description of 29 patients treated with flumazenil infusion and stabilised with clonazepam. Psychiatry Res. 2012; 198: 457-462. Ref.: https://goo.gl/ketbKE

4. Pérez MF, Maglio LE, Marchesini GR, Molina JC, Ramírez OA. Environmental changes modify the expression of Diazepam withdrawal. Behav Brain Res. 2002; 136: 75-81. Ref.: https://goo.gl/PWLV8f

5. Wolf ME. Addiction: making the connection between behavioral changes and neuronal plasticity in specific pathways. Mol Interv. 2002; 2: 146-157. Ref.: https://goo.gl/yBEPLQ

6. Monti MC, Almirón RS, Bignante EA, Ramírez OA. Changes in hippocampal arc protein expression and synaptic plasticity by the presentation of contextual cues linked to drug experience. Synapse. 2010; 64: 39-46. Ref.: https://goo.gl/yf352i

7. Taubenfeld SM, Muravieva EV, Garcia-Osta A, Alberini CM. Disrupting the memory of places induced by drugs of abuse weakens motivational withdrawal in a context-dependent manner. Proc Natl Acad Sci U.S.A. 2010; 107: 12345-12350. Ref.: https://goo.gl/3Jbs5m

8. Nestler EJ. Psychogenomics: opportunities for understanding addiction. J Neurosci. 2001; 21: 83248327. Ref.: https://goo.gl/XEw8H4

9. Ciccocioppo R, Sanna PP, Weiss F. Cocaine-predictive stimulus induces drug-seeking behavior and neural activation in limbic brain regions after multiple months of abstinence: reversal by $D(1)$ antagonists. Proc Natl Acad Sci U.S.A. 2001; 98: 1976-1981. Ref.: https://goo.gl/Vv6RK7

10. Kelley AE. Memory and addiction: shared neural circuitry and molecular mechanisms. Neuron. 2004; 44: 161-179. Ref.: https://goo.gl/tkC1ZZ

11. Eisch AJ, Mandyam CD. Drug dependence and addiction, II: adult neurogenesis and drug abuse. Am J Psychiatry. 2004; 161: 426. Ref.: https://goo.gl/euWy9n

12. Del Olmo N, Miguens M, Higuera-Matas A, Torres I, Garcia-Lecumberri C, et al. Enhancement of hippocampal long-term potentiation induced by cocaine self-administration is maintained during the extinction of this behavior. Brain Res. 2006; 1116: 120-126. Ref.: https://goo.gl/w3eTTg

13. Kim JJ, Fanselow MS. Modality-specific retrograde amnesia of fear. Science. 1992; 256 : 675-677. Ref.: https://goo.gl/oicVog

14. Phillips RG, LeDoux JE. Differential contribution of amygdala and hippocampus to cued and contextual fear conditioning. Behavioral neuroscience. 1992; 106: 274-285. Ref.: https://goo.gl/jr44xM

15. Martin SJ, Grimwood PD, Morris RG. Synaptic plasticity and memory: an evaluation of the hypothesis. Annual review of neuroscience. 2000; 23: 649-711. Ref.: https://goo.gl/WBf6vy

16. Perez MF, Nasif FJ, Marchesini GR, Maglio LE, Ramirez OA. Hippocampus and locus coeruleus activity on rats chronically treated with diazepam. Pharmacology Biochemistry and Behavior. 2001; 69: 431-438. Ref.: https://goo.gl/8Nnq9a

17. Prast $H$, Philippu A. Nitric oxide as modulator of neuronal function. Prog Neurobiol. 2001; 64: 51-68. Ref.: https://goo.gl/NBsCkh

18. Garthwaite J, Boulton CL. Nitric oxide signaling in the central nervous system. Annu Rev Physiol. 1995; 57: 683-706. Ref.: https://goo.gl/8D8VjX

19. Sousa AM, Prado WA. The dual effect of a nitric oxide donor in nociception. Brain Res. $2001 ; 897$ : 9-19. Ref.: https://goo.gl/2G8D97

20. Cardenas A, Moro MA, Hurtado O, Leza JC, Lizasoain I. Dual role of nitric oxide in adult neurogenesis. Brain Res Brain Res Rev. 2005; 50: 1-6. Ref.: https://goo.gl/MBJzpF

21. Yamada $K$, Noda $Y$, Nakayama $S$, Komori $Y$, Sugihara $H$, et al. Role of nitric oxide in learning and memory and in monoamine metabolism in the rat brain. Br J Pharmacol. 1995; 115: 852-858. Ref.: https://goo.gl/JJxrDs

22. Quock RM, Nguyen E. Possible involvement of nitric oxide in chlordiazepoxide-induced anxiolysis in mice. Life Sci. 1992; 51: 255-260. Ref.: https://goo.gl/eSmFQc 
23. Del-Bel EA, Oliveira PR, Oliveira JA, Mishra PK, Jobe PC, et al. Anticonvulsant and proconvulsant roles of nitric oxide in experimental epilepsy models. Braz J Med Biol Res. 1997; 30: 971-979. Ref.: https://goo.gl/3GmpVV

24. Uzbay IT, Oglesby MW. Nitric oxide and substance dependence. Neurosci Biobehav Rev. 2001; 25: 43-52. Ref.: https://goo.gl/br81aH

25. Nasif FJ, Hu XT, Ramirez OA, Perez MF. Inhibition of neuronal nitric oxide synthase prevents alterations in medial prefrontal cortex excitability induced by repeated cocaine administration. Psychopharmacology (Berl). 2011; 218: 323-330. Ref.: https://goo.gl/Y2oJXw

26. Gabach LA, Carlini VP, Monti MC, Maglio LE, De Barioglio SR, et al. Involvement of nNOS/NO/sGC/ cGMP signaling pathway in cocaine sensitization and in the associated hippocampal alterations: does phosphodiesterase 5 inhibition help to drug vulnerability? Psychopharmacology (Berl). 2013; 229: 41-50. Ref.: https://goo.gl/BPJLzy

27. Talarek S, Listos J, Fidecka S. Effect of nitric oxide synthase inhibitors on benzodiazepine withdrawal in mice and rats. Pharmacol Rep, 2011, vol: 63 pp. 680-689.

28. Rawls SM, Rodriguez T, Baron DA, Raffa RB. A nitric oxide synthase inhibitor (L-NAME) attenuates abstinence-induced withdrawal from both cocaine and a cannabinoid agonist (WIN 55212-2) in Planaria. Brain Res. 2006; 1099: 82-87. Ref.: https://goo.gl/6CYxx7

29. Jain R, Mukherjee $K$, Mohan D. Effects of nitric oxide synthase inhibitors in attenuating nicotine withdrawal in rats. Pharmacology biochemistry and behavior. 2008; 88: 473-480. Ref.: https://goo.gl/P3ug5B

30. Vaupel DB, Kimes AS, London ED. Nitric oxide synthase inhibitors. Preclinical studies of potential use for treatment of opioid withdrawal. Neuropsychopharmacology. 1995; 13: 315-322. Ref.: https://goo.gl/sdnuRt

31. Gabra BH, Afify EA, Daabees TT, Abou Zeit-Har MS. The role of the NO/NMDA pathways in the development of morphine withdrawal induced by naloxone in vitro. Pharmacol Res. 2005; 51: 319327. Ref.: https://goo.gl/KJJXWy

32. Uzbay IT, Erden BF, Tapanyigit EE, Kayaalp SO. Nitric oxide synthase inhibition attenuates signs of ethanol withdrawal in rats. Life Sci. 1997; 61: 2197-2209. Ref.: https://goo.gl/VMLjRU

33. Robbins TW, Everitt BJ. Neurobehavioural mechanisms of reward and motivation. Curr Opin Neurobiol. 1996; 6: 228-236. Ref.: https://goo.gl/UdZYbF

34. Griffiths RR, Weerts EM. Benzodiazepine self-administration in humans and laboratory animalsimplications for problems of long-term use and abuse. Psychopharmacology (Berl). 1997; 134: 1-37. Ref.: https://goo.gl/qhdZQF

35. Maren S. Pavlovian fear conditioning as a behavioral assay for hippocampus and amygdala function: cautions and caveats. Eur J Neurosci. 2008; 28: 1661-1666. Ref.: https://goo.gl/RZmj2j

36. Fontanesi LB, Ferreira R, Cabral A, Castilho VM, Brandao ML, et al. Brainstem areas activated by diazepam withdrawal as measured by Fos-protein immunoreactivity in rats. Brain Res. 2007; 1166 35-46. Ref.: https://goo.gl/Q7PNKZ

37. Almiron RS, Ramirez OA. Participation of dorsal raphe nucleus in the behavioral alteration observed after discontinuation of chronic diazepam administration: possible neural circuitry involved. Synapse. 2005; 56: 61-68. Ref.: https://goo.gl/W7FcYP

38. Shen G, Mohamed MS, Das P, Tietz El. Positive allosteric activation of GABAA receptors bidirectionally modulates hippocampal glutamate plasticity and behaviour. Biochem Soc Trans. 2009; 37: 1394-1398. Ref.: https://goo.gl/28QCid

39. Wang WS, Chen ZG, Liu WT, Chi ZQ, He L, et al. Dorsal hippocampal NMDA receptor blockade impairs extinction of naloxone-precipitated conditioned place aversion in acute morphine-treated rats by suppressing ERK and CREB phosphorylation in the basolateral amygdala. Br J Pharmacol. 2015; 172: 482-491. Ref.: https://goo.gl/DgVxu2

40. García-Pardo MP, Escobar-Valero C, Rodríguez-Arias M, Miñarro J, Aguilar MA. Involvement of NMDA glutamate receptors in the acquisition and reinstatement of the conditioned place preference induced by MDMA. Behav Pharmacol. 2015; 26: 411-417. Ref.: https://goo.gl/f4dRLL

41. Perez MF, Salmiron R, Ramirez OA. NMDA-NR1 and -NR2B subunits mRNA expression in the hippocampus of rats tolerantto Diazepam. Behav. Brain Res. 2003; 144; 119-124. Ref.: https://goo.gl/3fP9vB 
42. File SE, Fernandes C. Dizocilpine prevents the development of tolerance to the sedative effects of diazepam in rats. Pharmacol Biochem Behav. 1994; 47: 823-826. Ref.: https://goo.gl/QoyznY

43. Khanna JM, Shah G, Weiner J, Wu PH, Kalant H. Effect of NMDA receptor antagonists on rapid tolerance to ethanol. Eur J Pharmacol. 1993; 230: 23-31. Ref.: https://goo.gl/Ch1GAn

44. Trujillo KA, Akil H. Inhibition of morphine tolerance and dependence by the NMDA receptor antagonist MK-801. Science. 1991; 251: 85-87. Ref.: https://goo.gl/HQ3iiH

45. Almiron RS, Perez MF, Ramirez OA. MK-801 prevents the increased NMDA-NR1 and NR2B subunits mRNA expression observed in the hippocampus of rats tolerant to diazepam. Brain Res. 2004; 1008 : 54-60. Ref.: https://goo.gl/b8JymE

46. Garthwaite J, Garthwaite G, Palmer RM, Moncada S. NMDA receptor activation induces nitric oxide synthesis from arginine in rat brain slices. Eur $\mathrm{J}$ Pharmacol. 1989; 172: 413-416. Ref.: https://goo.gl/gk36Lf

47. Park JH, Straub VA, O'Shea M. Anterograde signaling by nitric oxide: characterization and in vitro reconstitution of an identified nitrergic synapse. J Neurosci. 1998; 18: 5463-5476. Ref.: https://goo.gl/qeeM8U

48. Bon $\mathrm{CL}$, Garthwaite J. On the role of nitric oxide in hippocampal long-term potentiation. J Neurosci. 2003; 23: 1941-1948. Ref.: https://goo.gl/uCx7fS

49. Smith ACW, Scofield MD, Heinsbroek JA, Gipson CD, Neuhofer D, et al. Accumbens nNOS Interneurons Regulate Cocaine Relapse. J Neurosci. 2017; 37: 742-756. Ref.: https://goo.gl/ZrGRa9

50. Rahmati B, Beik A. Prevention of morphine dependence and tolerance by Nepeta menthoides was accompanied by attenuation of Nitric oxide overproduction in male mice. J Ethnopharmacol. 2017; 199: 39-51. Ref.: https://goo.gl/Arw5ax

51. Okere $\mathrm{CO}$, Waterhouse BD. Nicotine withdrawal upregulates nitrergic and galaninergic activity in the rat dorsal raphe nucleus and locus coeruleus. Neurosci Lett. 2013; $536: 29-34$. Ref.: https://goo.gl/Daizf8

52. Faria MS, Muscara MN, Moreno Junior H, Teixeira SA, Dias HB, et al. Acute inhibition of nitric oxide synthesis induces anxiolysis in the plus maze test. Eur J Pharmacol. 1997; 323: 37-43. Ref.: https://goo.gl/Kj8JLE

53. Volke V, Wegener G, Vasar E. Augmentation of the NO-cGMP cascade induces anxiogenic-like effect in mice. J Physiol Pharmacol. 2003; 54: 653-660. Ref.: https://goo.gl/oqqvT3

54. Fanselow MS, Dong HW. Are the dorsal and ventral hippocampus functionally distinct structures? Neuron. 2010; 65: 7-19. Ref.: https://goo.gl/92kbGx 